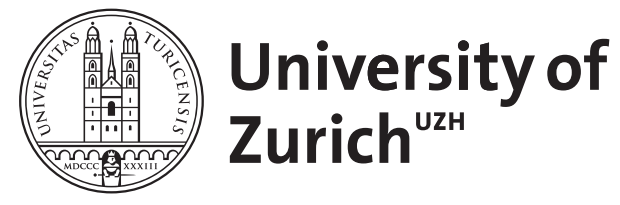

Zurich Open Repository and Archive

University of Zurich

University Library

Strickhofstrasse 39

CH-8057 Zurich

www.zora.uzh.ch

Year: 2013

Intraosseous inflammatory myofibroblastic tumor of the twelfth thoracic vertebra

Farshad, Mazda ; Bode, Beata ; Min, Kan

DOI: https://doi.org/10.2106/JBJS.CC.L.00316

Posted at the Zurich Open Repository and Archive, University of Zurich ZORA URL: https://doi.org/10.5167/uzh-91612

Journal Article

Published Version

Originally published at:

Farshad, Mazda; Bode, Beata; Min, Kan (2013). Intraosseous inflammatory myofibroblastic tumor of the twelfth thoracic vertebra. JBJS Case Connector, 3(2):e46 1.

DOI: https://doi.org/10.2106/JBJS.CC.L.00316 


\title{
Intraosseous Inflammatory Myofibroblastic Tumor of the Twelfth Thoracic Vertebra
}

\author{
Report of a Rare Case with Histological Diagnosis and Surgical Treatment
}

\author{
Mazda Farshad, MD, MPH, Beata Bode, MD, and Kan Min, MD
}

Investigation performed at Balgrist University Hospital and Institute of Surgical Pathology, University of Zurich, Zurich, Switzerland

\}

nflammatory myofibroblastic tumor (IMT) consisting of a spindle cell proliferation admixed with an inflammatory component is an uncommon mesenchymal lesion that

can arise in multiple anatomic locations ${ }^{1,2}$. Because of its heterogenic histologic appearance, different synonyms have been used throughout the literature, including inflammatory

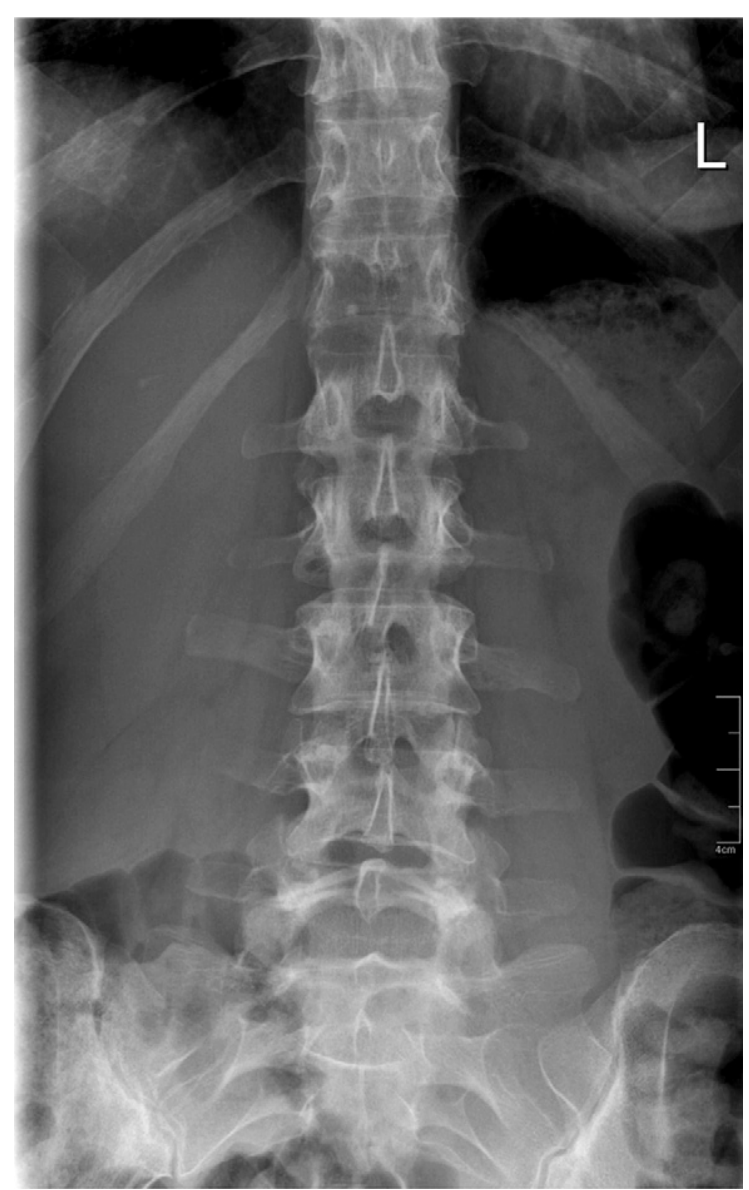

Fig. 1

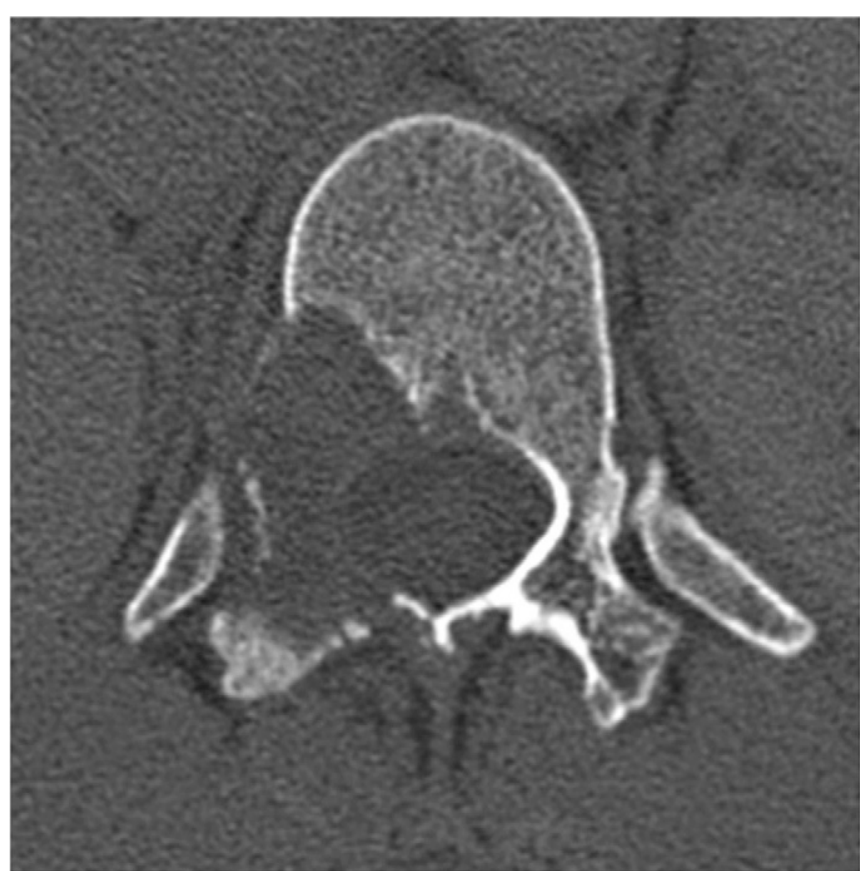

Fig. 2

Fig. 1 Radiograph showing destruction of the right pedicle of T12. Fig. 2 Axial CT of the lesion with a minimal marginal sclerosis.

Disclosure: None of the authors received payments or senvices, either directly or indirectly (i.e., via his or her institution), from a third party in support of any aspect of this work. None of the authors, or their institution(s), have had any financial relationship, in the thirty-six months prior to submission of this work, with any entity in the biomedical arena that could be perceived to influence or have the potential to influence what is written in this work. Also, no author has had any other relationships, or has engaged in any other activities, that could be perceived to influence or have the potential to influence what is written in this work. The complete Disclosures of Potential Conflicts of Interest submitted by authors are always provided with the online version of the article. 
JBJS Case Connector

Volume $3 \cdot$ Number $2 \cdot$ May 8, 2013
Intraosseous Inflammatory Myofibroblastic Tumor

of the Twelfth Thoracic Vertebra

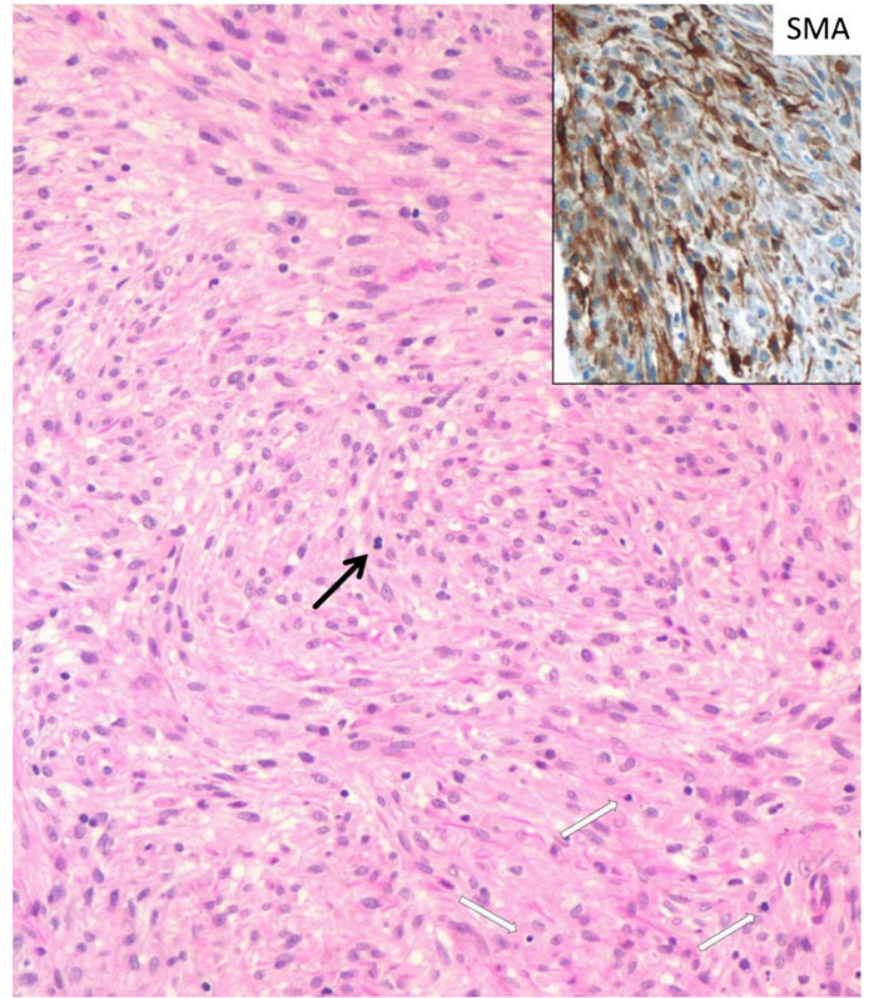

Fig. 3

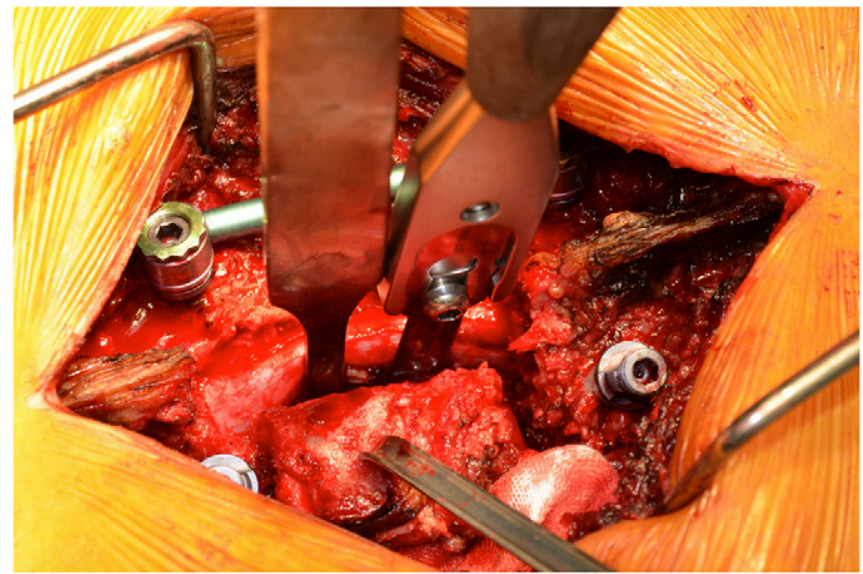

Fig. 4

Fig. 3 Core biopsy of the vertebral mass showing spindle cell proliferation with a few mitotic figures (black arrow) and some lymphocytes (white arrows) (hematoxylin and eosin stain, original magnification 100x). Inset (upper right) demonstrates focal immunohistochemical expression of smooth muscle actin (brown reaction product; original magnification $100 \times$ ). SMA = smooth muscle actin. Fig. 4 The dural sac is retracted to the left; two straight osteotomes were used for sagittal osteotomy of the vertebral body.

pseudotumor, fibromyxoid lesion, pseudosarcomatous myofibroblastic tumor, and plasma cell granuloma ${ }^{2}$. Although IMTs have been considered benign proliferation of myofibroblasts, they have potential for recurrence, persistent local growth ${ }^{3}$, and local aggressive behavior ${ }^{2,4}$. Their malignant potential is controversal ${ }^{5}$. The rare entity of multilocality has been described $^{6,7}$ and might even be interpreted as metastatic occurrence $^{8}$. Although very rare, even paraneoplastic symptoms have been attributed to IMT $^{9}$. While IMTs seem to localize predominantly in the viscera (e.g., lung) and soft tissue (e.g., mesentery and omentum $)^{2}$, they arise very infrequently in bone. Their occurrence has been reported in cranial bones $\mathrm{s}^{10-12}$, long bones ${ }^{13,14}$, the sacrum ${ }^{9}$, and the iliac bone ${ }^{15}$. IMTs in the spinal system are also reported ${ }^{16-19}$, but primary occurrence in a vertebral body is extremely rare ${ }^{1}$. Roberts et al. described a case of an IMT of the T10 vertebra compressing the thecal sac and involving the paravertebral muscles ${ }^{20}$, but it was unclear whether the IMT originated from the vertebral bone or from the surrounding soft tissues. We present a rare case of a localized IMT in the T12 vertebra, and we describe the difficulties involved in histological diagnosis and treatment. The patient was informed that data concerning the case would be submitted for publication, and she provided consent.

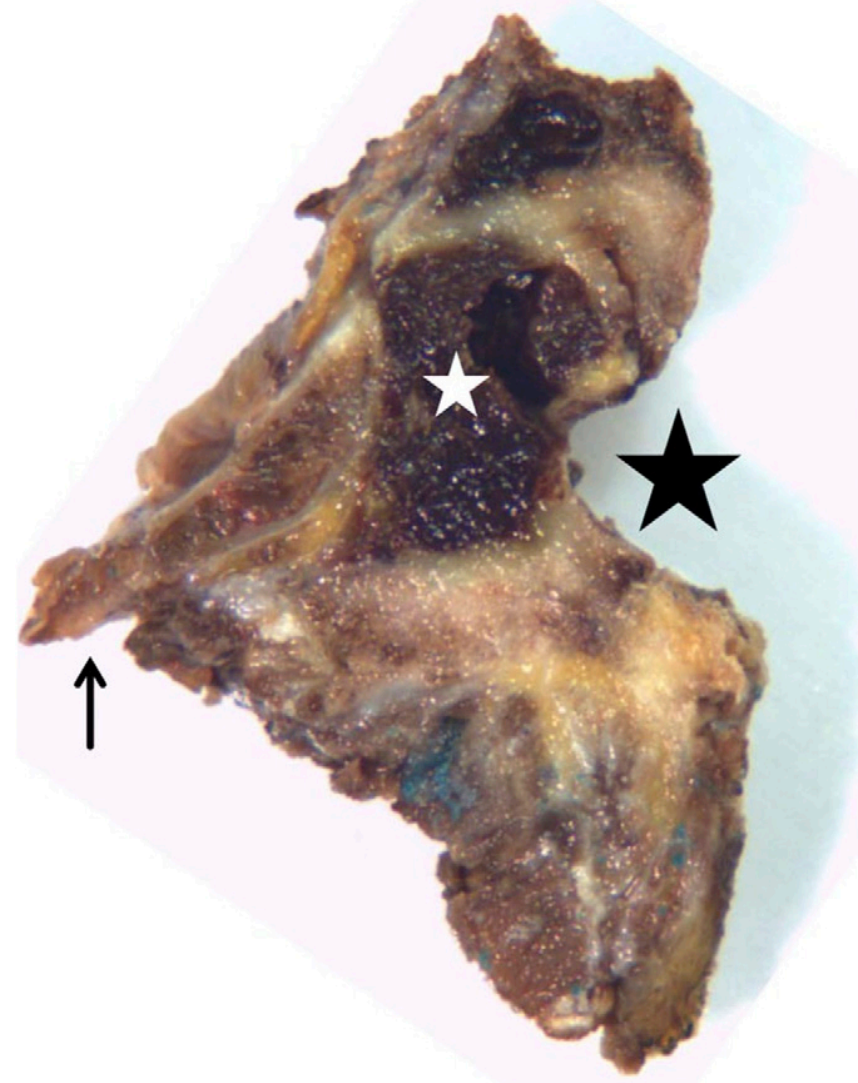

Fig. 5

An axial-cut section of the resected specimen with tumor mass (white star) (hemorrhagic after the core biopsies) in the pedicle, with infiltration of the vertebral body and costovertebral angle. The black star indicates the spinal canal; the arrow indicates the rib. 


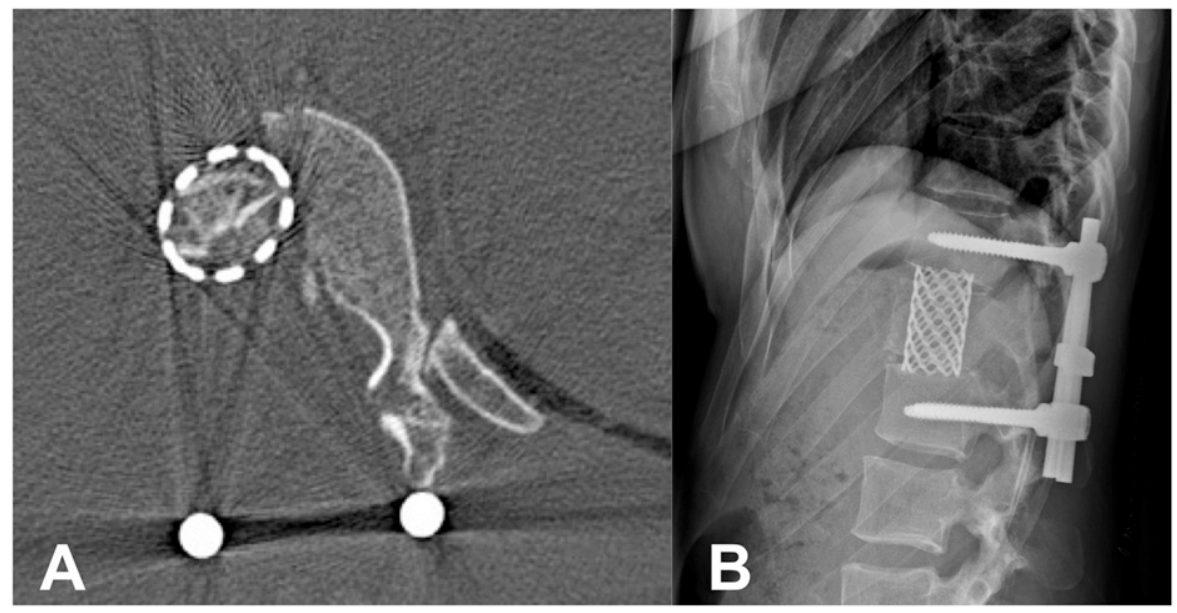

Fig. 6

Figs. 6-A and 6-B Imaging after reconstruction. Fig. 6-A An axial CT shows the extent of the partial vertebrectomy. Fig. 6-B A radiograph demonstrates the reconstruction with the titanium mesh cage and pedicle screw instrumentation on the right side.

\section{Case Report}

A thirty-seven-year-old woman presented with persistent and localized constant pain at the right costovertebral joint of the T12 vertebra. The medical history and clinical findings were normal. The radiographs showed destruction of the right pedicle of T12 (Fig. 1). Magnetic resonance imaging (MRI) revealed an expansive osteolytic mass $(35 \times 26 \times 20 \mathrm{~mm})$ in T12, which affected the right posterolateral aspect of the vertebral body, the right pedicle, the lamina, the inferior articular process, and the transverse process. Computed tomography (CT) showed slight sclerosis of the margins of the osteolysis, indicating a slow-growing lesion (Fig. 2). Two subsequent CT-guided core biopsies showed similar results and revealed a moderately cellular spindle cell proliferation with slight atypia, accompanied by some inflammatory cells (mostly lymphocytes and plasma cells) (Fig. 3). Immunohistochemical staining revealed focal positivity for smooth muscle actin ${ }^{21}$ (clone 1A4, dilution 1:20000; Sigma-Aldrich, Buchs, Switzerland) and cytokeratin (AE1/AE3, dilution 1:50; DAKO Schweiz AG, Baar, Switzerland) (Fig. 3). All other markers, including thyroid transcription factor 1, estrogen and progesterone receptors, and the $\mathrm{CDX} 2$ protein, as well as melanocytic markers, the remaining myogenic and neuroendocine markers, and epithelial membrane antigen, activating receptor-like kinase 1 (ALK1), CD34, CD117, and CD21, were negative. There were few mitoses, and the proliferation index, as measured by MIB-1 staining (clone 30-9, prediluted; Roche Diagnostics [Schweiz] AG, Rotkreuz, Switzerland), was low (below 5\%). There was no osteoid or cartilage matrix production. Staging procedure, including mammography and ultrasound of the breasts, CT, MRI, and positron emission tomography (PET)-CT, as well as gastroscopy and colonoscopy, failed to provide evidence of any other tumor manifestations, a primary tumor, or metastatic disease.

\section{Surgical Technique}

Through a midline skin incision, the T11 to L1 levels were exposed. On the right side, the lamina of T12 was not exposed, and a layer of muscle covering the lamina was left. Pedicle screws were placed in $\mathrm{T} 11$ and L1. Osteotomies were performed through the facet joints at T11-T12 and T12-L1 on the right side. After a right-sided costotransversectomy of T12, the lateral and anterior surfaces of the T12 body were exposed by blunt dissection of the pleura. A malleable retractor was inserted from the right side to the anterior surface of the vertebral body, displacing the aorta anteriorly; then, incisions were made into the intervertebral discs at T11-T12 and T12-L1. The T12 nerve root on the right side was sacrificed because of its proximity to the mass in the foramen. After the laminectomy at T11, the dural sac was retracted to the left, and a sagittal osteotomy at the midline of the T12 vertebral body was performed from posterior to anterior with use of ordinary straight osteotomes (Fig. 4). Then, the specimen, including the right half of the

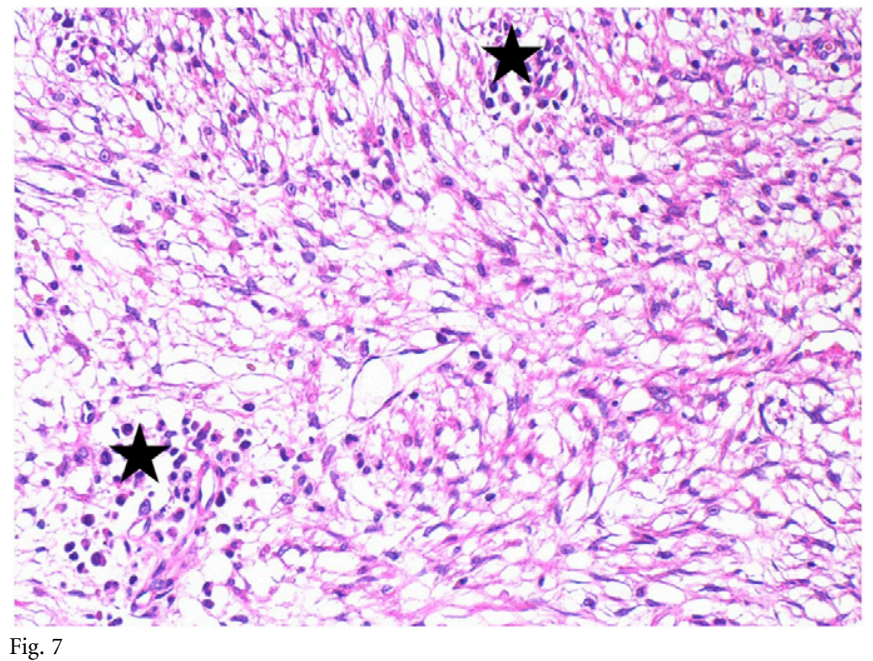

Fig. 7

The resection specimen showed areas of more loosely arranged bland spindle cells with focal collections (stars) of inflammatory cells (lymphocytes and granulocytes) (hematoxylin and eosin stain, original magnification 200x). 
JBJS Case Connector

Volume $3 \cdot$ Number $2 \cdot$ MaY 8, 2013
Intraosseous Inflammatory Myofibroblastic Tumor of the Twelfth Thoracic Vertebra

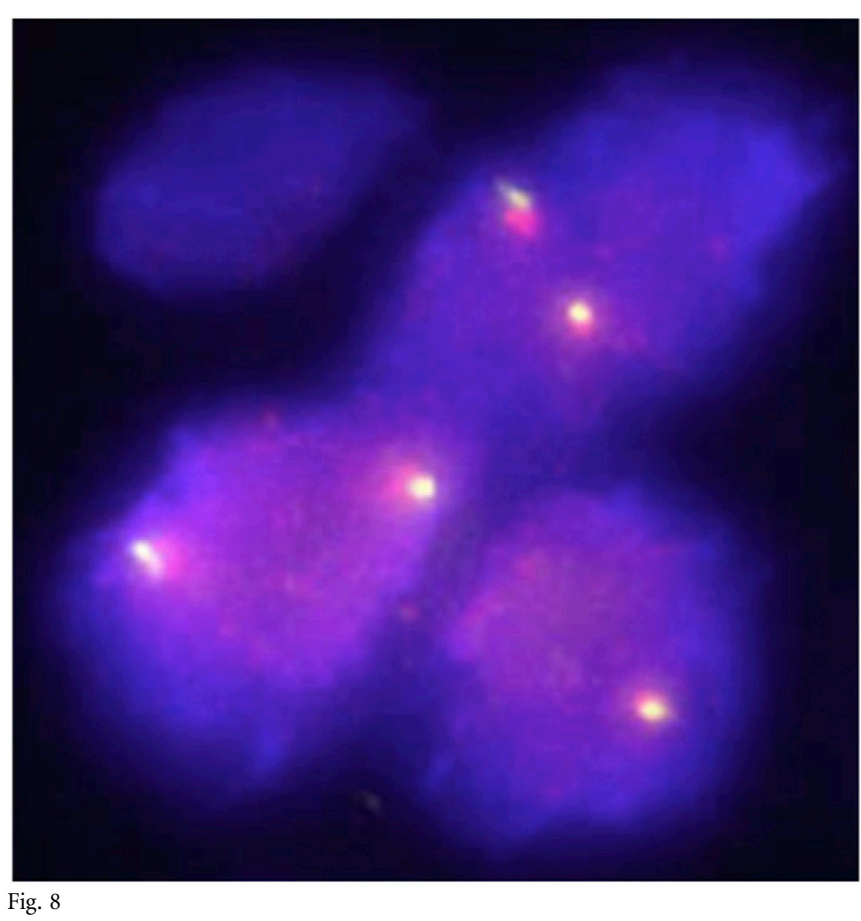

The FISH technique for the ALK1 gene showed one to two exclusively fused green and red signals in the nuclei of the tumor cells, indicating the lack of the rearrangement of this gene in the tumor tissue.

vertebral body with the upper and lower end plates, the pedicle, the articular facets, the transverse process, and part of the attached rib, was removed en bloc (Fig. 5). Reconstruction was achieved with a titanium mesh cage on the right side that was filled with autologous bone from the iliac crest (Fig. 6). The patient's postoperative course was uneventful. Weight-bearing and walking without bracing began on the first postoperative day.

At the six-week follow-up, the patient was asymptomatic and was reintegrated into normal daily life. Adjuvant therapy was not instituted. At the six-month follow-up, there was no evidence of a recurrence of the lesion on MRI or CT. At the twelve-month follow-up, the patient was pain-free, and there was evidence of solid fusion without any signs of recurrence on a repeat CT.

\section{Histological Analysis}

Histologically, the tumor consisted of monomorphic spindle cells arranged vaguely in loose fascicles, with focal areas of edematous matrix (Fig. 7) and infiltrates of inflammatory cells (lymphocytes, plasma cells, and granulocytes). The main tumor mass (Fig. 5) was found in the osseous structures of the pedicle, with spreading in the vertebral body; there was also infiltration of the soft tissue of the costovertebral angle. No osteoid production or intralesional cartilage was found. The mitotic figures were scarce (less than two in ten high-power fields). The tumor cells showed myofibroblastic phenotype with slender cytoplasm and oval nuclei with small nucleoli. In concordance with the preceding biopsy, focal expression of smooth muscle actin and cytokeratin was found, while all other markers, including ALK1, remained negative. Fluorescence in situ hybridization (FISH) failed to demonstrate the rearrangement of the ALK1 gene (Fig. 8). IMT was diagnosed. No tumor was found within $3 \mathrm{~mm}$ of the resection margin.

\section{Discussion}

A $\mathrm{n}$ IMT consisting of a spindle cell proliferation admixed $\mathrm{A}_{\text {with an inflammatory component is an uncommon me- }}$ senchymal lesion that can arise in multiple anatomic locations ${ }^{2}$. We present a rare case of a localized, ALK1-FISH negative IMT in the T12 vertebra. Once considered a reactive process, an IMT is currently classified as a neoplastic lesion ${ }^{22}$; rearrangement of the ALK1 gene, located on chromosome region 2p23, and coding for a tyrosine kinase receptor member of the insulin growth factor receptor superfamily are found in approximately $50 \%$ of cases, indicating a specific genetic background for this entity. The availability of ALK1 inhibitors (e.g., crizotinib) may be a therapeutic option in ALK1-positive aggressive $\mathrm{IMTs}^{23}$. The IMT case described in our report did not show the rearrangement of the ALK1 gene with the FISH technique (Fig. 8).

Because IMTs are very rare and manifest with a wide range of presentations depending on location and extent, no established guidelines exist regarding the best treatment modality. An overall recurrence rate as high as $8 \%$ to $25 \%{ }^{2,22}$ has been reported with incomplete resection, and removal with wide margins is recommended ${ }^{2}$. Although the role of adjunctive treatment is largely unknown, it has been suggested that adjuvant chemotherapy be considered in conjunction with radiation therapy if complete resection cannot be achieved $^{2}$. This case report illustrates the difficulties in histological diagnosis of IMTs, as well as the successful surgical treatment with complete en bloc resection. At the one-year follow-up, the patient was free of symptoms and there was no evidence of recurrence on repeat CT. In addition, histology showed that no tumor was found within $3 \mathrm{~mm}$ of the resection margin. Therefore, recurrence is not expected, and the necessity for additional follow-up radiographs is unknown and debatable.

Mazda Farshad, MD, MPH

Kan Min, MD

Department of Orthopaedics,

University of Zurich,

Balgrist University Hospital,

Forchstrasse 340,

8008 Zurich, Switzerland.

E-mail address for M. Farshad: mazda.farshad@balgrist.ch

Beata Bode, MD

Institute of Surgical Pathology,

University Hospital Zurich,

Ramistrasse 71, 8006 Zurich, Switzerland 


\section{References}

1. Chang $\mathrm{H}$, Park JB, Kim KW. Intraosseous calcifying pseudotumor of the axis: a case report. Spine (Phila Pa 1976). 2000 Apr 15;25(8):1036-9.

2. Kovach SJ, Fischer AC, Katzman PJ, Salloum RM, Ettinghausen SE, Madeb R, Koniaris LG. Inflammatory myofibroblastic tumors. J Surg Oncol. 2006 Oct 1;94(5):385-91.

3. Coffin CM, Watterson J, Priest JR, Dehner LP. Extrapulmonary inflammatory myofibroblastic tumor (inflammatory pseudotumor). A clinicopathologic and immunohistochemical study of 84 cases. Am J Surg Pathol. 1995 Aug;19(8):859-72.

4. Hedlund GL, Navoy JF, Galliani CA, Johnson WH Jr. Aggressive manifestations of inflammatory pulmonary pseudotumor in children. Pediatr Radiol. 1999 Feb;29(2):112-6.

5. Dahabreh J, Zisis C, Arnogiannaki N, Katis K. Inflammatory pseudotumor: a controversial entity. Eur J Cardiothorac Surg. 1999 Dec;16(6):670-3.

6. Ishihara M, Izumoto S, Iwatsuki K, Yoshimine T. Immunohistochemical study of multiple inflammatory pseudotumors with both brain and spinal cord involvement—case report. Neurol Med Chir (Tokyo). 2010;50(3):246-50.

7. Sasagawa Y, Akai T, Itou S, lizuka H. Multiple intraosseous inflammatory myofibroblastic tumors presenting with an aggressive clinical course: case report. Neurosurgery. 2011 Oct;69(4):E1010-5; discussion E1015-6.

8. Petridis AK, Hempelmann RG, Hugo HH, Eichmann T, Mehdorn HM. Metastatic low-grade inflammatory myofibroblastic tumor (IMT) in the central nervous system of a 29-year-old male patient. Clin Neuropathol. 2004 Jul-Aug;23(4):158-66.

9. Allanore Y, Pham XV, Clerc DA, Menkès CJ, Kahan A. Sacral inflammatory pseudotumor revealed by paraneoplastic syndrome. Rheumatol Int. 2004 May:24(3):166-8. Epub 2003 Dec 02.

10. Ghosal N, Roy R, Reddy K, Hegde AS. Inflammatory myofibroblastic tumor parieto-occipital bone. Indian J Pathol Microbiol. 2010 Jul-Sep;53(3):529-31.

11. Papanikolaou V, Nikitakis N, Marinakis K, Bousiotou A, Xenelis I. Inflammatory myofibroblastic tumor of the temporal bone. Otol Neurotol. 2012 Jan;33(1):e5-6.

12. Santaolalla-Montoya $F$, Ereño $C$, Zabala $A$, Carrasco A, Martínez-lbargüen $A$, SánchezFernández JM. Inflammatory myofibroblastic tumor of the temporal bone: a histologically nonmalignant lesion with fatal outcome. Skull Base. 2008 Sep;18(5):339-43.

13. Chen J, Li H, Yang Z, Liu Q, Gao M, Jiang X, Cai Z, Liang B, Jiang Y. Inflammatory myofibroblastic tumor of bone: two cases occurring in long bone. Skeletal Radiol. 2011 Jan;40(1):117-22. Epub 2010 Jul 22.
14. Sciot R, Dal Cin P, Fletcher CD, Hernandez JM, Garcia JL, Samson I, Ramos L, Brys P, Van Damme B, Van den Berghe H. Inflammatory myofibroblastic tumor of bone: report of two cases with evidence of clonal chromosomal changes. Am J Surg Pathol. 1997 Oct;21(10):1166-72.

15. Watanabe $K$, Tajino $T$, Sekiguchi $M$, Suzuki T. Inflammatory myofibroblastic tumor (inflammatory fibrosarcoma) of the bone. Arch Pathol Lab Med. 2000 Oct;124(10):1514-7.

16. Boutarbouch M, Arkha Y, Rifi L, Derraz S, El Ouahabi A, El Khamlichi A. Intradural cervical inflammatory pseudotumor mimicking epidural hematoma in a pregnant woman: case report and review of the literature. Surg Neurol. 2008 Mar;69(3):3025. Epub 2007 Sep 04

17. Seol HJ, Kim SS, Kim JE, Lee SH, Won JY. Inflammatory pseudotumor in the epidural space of the thoracic spine: a case report and literature review of MR imaging findings. AJNR Am J Neuroradiol. 2005 Nov-Dec;26(10):2667-70.

18. Yoon SH, Kim KJ, Chung SK, Kim HJ, Choe G, Chung SB, Jin YJ. Inflammatory myofibroblastic tumor in the intradural extramedullary space of the lumbar spine with spondylolisthesis: case report and review of the literature. Eur Spine J. 2010 Jul:19(Suppl 2):S153-7. Epub 2009 Nov 26.

19. Zemmoura I, Hamlat A, Morandi X. Intradural extramedullary spinal inflammatory myofibroblastic tumor: case report and literature review. Eur Spine J. 2011 Jul;20(Suppl 2):S330-5. Epub 2011 Apr 06.

20. Roberts GA, Eldridge PR, Mackenzie JM. Case report: inflammatory pseudotumour of the spine, with literature review. Br J Neurosurg. 1997 Dec;11(6): 570-2.

21. Piwowar HA, Day RS, Fridsma DB. Sharing detailed research data is associated with increased citation rate. PLoS One. 2007;2(3):e308. Epub 2007 Mar 21. 22. Fletcher CDM, Unni KK, Mertens F. Pathology \& genetics of tumours of soft tissue and bone. Lyon, IARC; 2002. Inflammatory myofibroblastic tumour; p 91-93. 23. Butrynski JE, D'Adamo DR, Hornick JL, Dal Cin P, Antonescu CR, Jhanwar SC, Ladanyi M, Capelletti M, Rodig SJ, Ramaiya N, Kwak EL, Clark JW, Wilner KD, Christensen JG, Jänne PA, Maki RG, Demetri GD, Shapiro Gl. Crizotinib in ALKrearranged inflammatory myofibroblastic tumor. N Engl J Med. 2010 Oct 28;363(18):1727-33. 